ПОЛИВАЕВА Надежда Павловна - доктор политических наук, доцент; заведующий кафедрой социально-гуманитарных и финансово-правовых дисциплин Воронежского института ФСИН России (394072, Россия, г. Воронеж, Иркутская ул., 1A; nadezhda-polivaeva.n@yandex.ru)

\title{
ТЕОРЕТИЧЕСКИЕ РАЗМЫШЛЕНИЯ О МАССОВОМ СОЗНАНИИ: МОЖНО ЛИ НАЙТИ СУЩНОСТЬ?
}

\begin{abstract}
Аннотация. В статье предпринята попытка теоретического обзора и обобщения некоторых ключевых свойств массового сознания, выявленных ведущими современными учеными. Ее основное содержание заключено в названии, предполагающем поиск ответа на вопрос, обладает ли феномен массового сознания сущностью. Через попытку найти некие устойчивые свойства массового сознания автор обозначает его сущностное содержание. Разработка проблем массового сознания в советской научной литературе сдерживалась в силу того, что оно рассматривалось в качестве атрибута массового общества и как альтернатива классовому сознанию. В статье рассматриваются социологический, социальнопсихологический, деятельностный и другие подходы к трактовкам массового сознания, особенности, отличающие его от обыденного и специализированного сознания, а также коллективного сознания и общественного мнения. Пока не исследована надлежащим образом проблема слоев и полей массового сознания, его исторических типов.

Ключевые слова: массовое сознание, масса, деятельность масс, коллективное сознание, коллективное бессознательное, обыденное сознание, общественное мнение, массовое общество, общественное сознание
\end{abstract}

\begin{abstract}
A ктуальность проблематики статьи определяется, на наш взгляд, тем, что ряд исследователей предлагают перейти от использования «старых» терминов, таких как «масса», «сознание масс», к понятию «множество» [Патрушев, Филиппова 2017: 28]. Речь у современных отечественных теоретиков идет о том, что в позднеиндустриальном обществе массы как нерасчлененное множество заменяются разнообразными множественными носителями социальной и политической субъективности, для которых особую ценность имеют права и свободы человека. Данная позиция созвучна взглядам зарубежных исследователей, отмечающих, что политика в своем истинном значении - это не внутриэлитные контакты и взаимодействия, а активность масс граждан [Норт, Уоллис, Вайнгаст 2011: 215], в той или иной мере способствующая демократической парадигме государственной власти.

Мы солидарны с подходом профессора А.И. Соловьева, который, признавая трансформацию «базовых параметров идеальной составляющей деятельности формально понимаемого массового актора», не снимает с повестки дня и вопрос о роли сознания масс, или множеств, в реальной политической действительности [Соловьев 2017: 190].

На наш взгляд, массовое сознание - понятие не нормативное, а описательное. Слабость его в том, что данное понятие в известном смысле ничего не говорит о специфике обозначаемого им содержания. Наряду с этим значение термина чаще всего связывают с возможностью говорить о способности носителя (масс) непосредственно отражать действительность на обыденном уровне, а также о способности усваивать многие идеи и взгляды, присущие специализированному сознанию. Оно включает в свое поле некий синтез как специализированного сознания, так и обыденного, хотя и не во всем объеме. По акцентуациям массового сознания (господствующим в обществе атмосфере, настрою, общественному мнению) можно судить об общественном сознании в определенный исторический период развития данного социума [Поливаева 2009: 189-190].
\end{abstract}


По сути, самым распространенным взглядом на массовое сознание в отечественной социально-гуманитарной науке выступает приравнивание его к общественному мнению [Грушин 1967]. Этот подход характерен для прикладной социологии, которая изучает вербальные мнения и позиции с точки зрения частоты использования тех или иных формулировок респондентов. Общественное мнение «может пониматься как некое мнение, составленное из нескольких мнений, имеющих место в общественности, а лучше - как центральная тенденция, устанавливаемая в борьбе между этими отдельными мнениями и, следовательно, оформленная соответствующей силой противодействия, которая между ними существует» [Блумер 1994: 189]. Оно свидетельствует об актуальности какой-либо совокупности идей и представлений для общества в конкретной ситуации. Данная совокупность более значима по сравнению с другими существующими представлениями и суждениями.

Эмпирический анализ массового сознания не позволяет объяснить один из парадоксов функционирования феномена: идеи, взгляды, представления, являясь актуальными для значительной части членов общества, могут и не выражать реальное мнение большинства. Напротив, они могут складываться при определенных условиях под влиянием меньшинства (интеллектуалов, популярных лидеров, тех или иных партий и т.д.) [Любивый 1993: 103].

Изучение массового сознания в психологических теориях Г. Лебона, Ж. Сигеле, Г. Тарда, В. Бехтерева, Л. Войтоловского и др. привело к объяснению его как результата деятельности масс. Человек «массы» подчиняется общим законам функционирования массовых общностей. Любые социальноклассовые различия фактически исчезают в тех или иных массовидных процессах и действиях. Г. Лебон, рассуждая по этому поводу, образно говорил о том, что «толпа академиков равна толпе черни» [Лебон 1995: 161]. Тем самым ученый подчеркивал идентичные субъективные качества, свойственные массовым общностям при их образовании и функционировании.

В социальной психологии для интерпретации энергии психического напряжения, возбуждения применяется понятие «коллективное бессознательное». Так, например, Г. Тард отмечает, что масса начинается с соединения этой энергии внутри некой совокупности людей и порождения затем дополнительной энергии, которая останавливает, нейтрализует рационально-логические компоненты субъективной реальности индивида [Тард 1892: 67]. Психологическая общность индивидов выступает одним из наиболее ярких доказательств существования единого бессознательного первоначала, определяющего движение исторического процесса на том или ином этапе. Но данный подход, по сути, отождествляет массовое сознание и коллективную психологию.

Концепцию коллективного бессознательного по-своему развивал Э. Дюркгейм. В ней социолог анализирует социальную обусловленность коллективного сознания и его довлеющее воздействие на индивидуальное сознание. Коллективное сознание выражает вещественные, пространственные связи и отношения, существующие в реальной жизнедеятельности людей, выступает своеобразной субъективной проекцией этой жизнедеятельности в сфере индивидуальной психики [Дюркгейм 1991: 80]. Оно отличается от индивидуального сознания тем, что известное число состояний сознания является общим для всех членов одного и того же общества. Чем больше согласованы представления и верования, тем меньше они оставляют места индивидуальным расхождениям.

Исследуемое Э. Дюркгеймом коллективное сознание вероятнее следует соотносить не с групповым, а с общественным сознанием в целом [Гофман 1991: 564]. Вместе с тем важно подчеркнуть, что именно от Дюркгейма идет понима- 
ние коллективного сознания как надындивидуального феномена, имеющего собственное содержание, не сводимого к сумме индивидуальных сознаний.

Начиная с 1960-х гг, в российской философской и социологической мысли феномен массового сознания изучается в рамках деятельностного подхода. Главное в данном подходе, как известно, заключается не столько в анализе закономерностей развертывания субъективного мыслительного процесса, сколько в вычленении внешних параметров его проявления. Массовое сознание выделяется не в зависимости от его содержательных характеристик, когнитивных способностей и т.д., а на основе особенностей его носителя-субъекта. Иначе говоря, по мнению многих авторов, неустойчивость, синкретичность, пластичность феномена массового сознания не позволяет уловить его природу никаким иным способом, кроме как через его субъекта-носителя - массы, те или иные массовые объединения людей.

Специфическими свойствами масс являются статистический характер, стохастичность формирования, ситуативность существования и явно гетерогенная природа. Эти черты рассматриваются в качестве сущностных признаков. Из них вытекают определения массового сознания как эксгруппового (или межгруппового) сознания, сознания внеструктурных социальных образований так называемых внеструктурных островов в групповой структуре социума, как бы плавающих в составе более широкого социального целого [Дилигенский 1986: 11, 14].

Ценность данной позиции заключается в том, что массовое сознание как бы вводится в систему реальной социальной деятельности индивидов. Перевод проблемы в плоскость практического действия открывает перспективы для исследования содержательных компонентов массового сознания, в т.ч. и для исследования его политических образований, реально влияющих на поведение различных категорий населения. Вместе с тем сами авторы данной точки зрения справедливо замечали, что «не каждый тип и вид массового сознания может быть “жестко” привязан к какому-то одному определенному типу и виду массовой общности» и что «некоторые типы и виды масс (телеаудитория, например) складываются на основе способов существования и деятельности данных общностей, но без использования характеристик их сознания» [Грушин 1994: 281].

Американский социолог Д. Белл подчеркивал, что многочисленные теории массового общества являются недостаточно четкими потому, что термин «массы» не совсем ясен. Пытаясь прояснить его, Д. Белл выделил пять основных значений: 1) массы как недифференцированное множество; 2) массы как синоним невежественности; 3) массы как механизированное общество; 4) массы как бюрократизированное общество; 5) масса как толпа [Малькова 1992].

Полагаем, что столь односторонний взгляд не исчерпывает содержания и особенностей масс, их поведения в различных общественно-политических ситуациях. Массы многослойны по своей структуре, противоречивы, способны к быстрым, неожиданным изменениям в одних направлениях и определенным «окостенениям» - в других. Масса всегда облечена в те или иные конкретные формы. Она не обязательно предполагает сбор (или сборище) множества людей на площади, улице, стадионе или ином пространстве. С точки зрения свойств сознания, приверженности определенным стереотипам поведения и рефлексиям человек может принадлежать массе, не выходя из собственной квартиры.

Масса отличается от беспорядочной толпы людей тем, что обладает единством идеи, настроения, воли и поведения. Содержание и направленность этих четырех компонентов могут быть самыми разнообразными. Главное, что они объединяют толпу в массу. Здесь можно привести такие примеры, как движение луддитов в Англии конца XVIII - начала XIX в., еврейские погромы в России в 
начале ХХ в., суды Линча в США и т.д. В современную эпоху заметно интенсифицировался такой способ «раскачать» массу на бессмысленные выступления, как религиозный фанатизм (например, в Индии, Сирии) или воинствующий национализм (например, в Югославии или на Кавказе).

Итак, с одной стороны, массовое сознание проявляется только в деятельности массы, но, с другой - справедливо и то, что оно, как уже отмечалось, обладая некой самостоятельностью, способно определенным образом воздействовать на «поверхность» или «глубину» чувств, восприятия, эмоций людей. Фактически здесь возникают две сложные проблемы: проблема четкого разграничения самих коллективных (массовидных) проявлений, выявления специфики субъективных практик, релевантных этим проявлениям, и проблема внешних влияний, стимулирующих ту или иную практику. Именно эти проблемы обусловили ведущие направления исследования феномена массового сознания в современной западной социологии и социальной психологии. Речь идет о целом ряде концепций - концепции социальных представлений С. Московичи, одномерного мышления Г. Маркузе, атомизированного индивида X. Арендт и Л. Бодрияра, восстания масс X. Ортеги-и-Гассета, массовой коммуникации А. Моля, коллективного поведения Г. Блумера и т.п.

В этих концепциях феномен массового сознания интерпретируется через деятельность атомизированной массовой общности, возникшей в процессе коммуникационного взаимодействия в эпоху перехода от индустриального общества к постиндустриальному. Его характеристики варьируются от «хаотизированного», «разорванного», «свидетельствующего об эмоциональной фрустрации “Я” ( (Л. Бодрияр) или «замкнувшегося на себе» (Х. Арендт) сознания до «формально рационализированного» (Г. Маркузе) сознания, в котором «плавятся» представления множества людей, оказавшихся под властью социального авторитета, перенесенного в область бессознательного (С. Московичи). Эпоха массового общества - это эпоха предельно стандартизированного, унифицированного образа мысли и деятельности миллионов людей.

Согласно Х. Ортеге-и-Гассету, в эту эпоху на арену истории вышел относительно новый тип человека - человек массы. Он делает специальную оговорку, что деление общества на массы и избранное меньшинство - это деление не на социальные классы, а на типы людей; это совсем не иерархическое различие «высших» и «низших»: в каждом классе можно найти и «массу», и настоящее «избранное меньшинство» [Ортега-и-Гассет 1989: 122].

Х. Ортега-и-Гассет делает вывод, что упадок элиты - трагедия XX в. Дихотомия «элита - масса» представляет собой норму жизни общества. Трагедия общества начинается там, где имеет место вторжение масс в управленческую и творческую деятельность элиты.

Концепция испанского философа, на наш взгляд, характеризуется чрезмерной акцентацией на негативных сторонах массы и массового сознания. Последнее рассматривается им исключительно как совокупность волевых импульсов, чувственных образов, настроений, влечений, эмоций и т.п.

В отечественной науке массовое сознание, как было отмечено ранее, понимается шире - как совокупность «самых разнообразных по их гносеологической и социальной природе духовных образований, не ограниченных лишь формами психики, относящимся к “разделам”, сферам, уровням... психологии и идеологии, эмоций и логики, образов и реакций, обыденного и теоретического знания, рациональных и иррациональных (в том числе фантастических) представлений и т.д.» [Грушин 1994: 286]. В него входят самые разнообразные идеи и представления: политические, экономические, нравственные, философские, эстетические и т.д. Более того, природу субъекта массового сознания отече- 
ственные исследователи правомерно рассматривают одновременно и как индивидуальную, и как групповую. Данный вид сознания проявляется и функционирует как на уровне личности, так и на уровне массовых общностей, отражая их потребности, интересы, ценности и цели. Иначе говоря, граждане, являясь членами разных социальных групп и вместе с тем - каких-либо массовых общностей и образований, одновременно представляют собой носителей массового сознания, оставаясь при этом «специфическими индивидуальностями». Это не означает, что содержание массового сознания всеохватно и беспредельно, - оно значительно проигрывает содержанию общественного сознания в целом и тем более содержанию совокупного индивидуального сознания [Грушин 1994: 305].

Массовое сознание (в т.ч. его политическую составляющую) можно определить как вид общественного сознания, выделяемый в составе последнего наряду со специализированным и групповым сознанием и связанный, как уже отмечалось, с функционированием особого рода социальных общностей - масс. В отличие от группового сознания, у него отсутствует некий содержательный стержень, обнаруживаемый, например, в классовом сознании, особенно при трансформации условий существования класса.

В массовом сознании уживаются как метафизические, так и диалектические стороны. Происходит это, вероятно, потому, что оно постоянно переживает периоды спада и подъема. В течение этих волн накапливается разнообразный социальный опыт. Именно он играет наиважнейшую роль в формировании и развитии массового сознания. Без учета его содержания нельзя понять конкретные модификации и формы выражения массовых умонастроений, представлений, взглядов и чувств.

Нелишне заметить, что понятие «массы» активно использовалось в трудах классиков марксизма. Марксисты ни в коей мере не преуменьшали внутреннюю дифференциацию обозначаемого этим понятием феномена. Они подчеркивали неоднородность масс, обращали внимание на тот факт, что массы «образуют внутри себя и между собой весьма массовые противоположности». Понятие «массы» имеет в работах классиков марксизма множество оттенков. Наряду с такими категориями как «массы класса», «широкие массы», в них присутствует, например, понятие «ограниченной массы», т.е. не охватывающей всей совокупности населения [Маркс 1956: 171]. Наряду с понятием «массы» в них широко используется в качестве своего рода синонима и такой термин, как «трудящиеся».

Хотя природа и свойства массового сознания плохо поддаются фиксации и описанию, ключевой проблемой политической науки остается овладение инструментами диагностики, оперативных и объективных замеров его у разных социальных групп и общностей. В этой связи важным теоретико-методологическим выводом, как считал Б. Грушин, является идея о необходимости различать: а) моментальные, меняющиеся характеристики массового сознания, которые проявляются в его отношении к отдельным объектам действительности; и б) глубинные, устойчивые свойства, проявляющиеся одновременно в отношении многих объектов. Но как это сделать, зависит от целого ряда факторов, в частности от исследовательских задач и концепций.

На наш взгляд, к устойчивым свойствам рассматриваемого феномена относится колоссальная роль веры и надежды на лучшее будущее, на осуществление справедливости, хотя бы когда-нибудь, и большей, чем есть в действительности. Это не означает, что массовое сознание всегда оптимистично. Дело в другом: в нем неистребима какая-то инвариантная тяга к лучшей, «более правильной» жизни. И состояние апатии, часто ему свойственное, подтверждает именно эту имманентную черту. Если вера не подкрепляется на практике, то массы впадают в пессимизм, уныние, снижающие их активную жизнедеятель- 
ность. Если же вера подпитывается какими-либо очевидными основаниями для ее реанимации или усиления, то она превращается в уверенность. Массы переживают состояние эмоционального воодушевления, которое, заметим, может иметь разную социально-политическую направленность.

Таким образом, понятие «массовое сознание» близко к понятию «общественное сознание». Переплетаясь, они зачастую заменяют друг друга в определенном контексте [Разум... 2017: 14, 161-163]. Выделяя главное в многочисленных определениях общественного сознания, можно сказать, что оно - высшая ступень абстракции, в нем создаются инварианты, которые обобщают и фиксируют лишь наиболее существенные отношения и связи практической деятельности; эти отношения и связи здесь приобретают форму законов, научных теорий, произведений искусства и т.д. Термин «общественное сознание» ориентирует внимание на «состояние умов в ту или иную эпоху» [Холодковский 2018: 177]. Массовое сознание же, являясь многомерным, неоднородным, крайне противоречивым образованием, фиксирует прежде всего эмоционально-чувственную (оценочную), психологическую сферу социума, ценностные ориентации и экспектации его сегментов.

Вместе с тем каждая ступень в исторической динамике российского общества сопряжена прежде всего с «революцией сверху», с переменами во властных структурах, с изменениями в политическом мышлении элиты. Применяя, как и любая другая элита, в своем отношении к массам политику кнута и пряника, российская власть все же гораздо последовательнее использовала силовые методы и средства для достижения своих групповых целей. В то же время авторитарный характер российской власти нередко сочетался с авторитарным комплексом в массовом сознании.

«Сущностное содержание», «смысловое ядро» применительно к массовому сознанию может весьма условно интерпретироваться как постоянное пульсирование между периодами спада (разочарования, апатии) и подъема (надежды и веры). Это пульсирование всегда обусловлено внешними изменениями, характером конкретно-исторических этапов развития общества. В современной России имеются веские объективные основания для вывода о том, что потенциал социальных настроений достиг той критической черты, когда массовое сознание становится восприимчивым к нарушению гражданско-правовых норм, а также одновременно и к радикальным сдвигам. Но достаточно трудно определить грань между массовым сознанием как психическим состоянием общества (или общности) и теми факторами, которые участвуют в формировании его перерастания в социальное действие. Психологическая готовность к его началу никогда не бывает равнозначной всему сложнейшему процессу работы на пути к ожидаемому результату. Это значит, что стартовая готовность носителя массового сознания к началу какого-то действия не тождественна его социально-психологической нацеленности на борьбу за те лозунги, которые отражают чаяния масс.

\section{Список литературы}

Блумер Г. 1994. Коллективное поведение. - Американская социологическая мысль (под ред. В.Н. Добренькова). М.: Изд-во МГУ. С. 90-189.

Гофман А.Б. 1991. О социологии Э. Дюркгейма. - Дюркгейм Э. О разделении общественного труда: Метод социологии. М.: Наука. 575 с.

Грушин Б.А. 1967. Мнение о мире и мир мнений: проблемы методологии исследования общественного мнения. М.: Политиздат. 400 с.

Грушин Б.А. 1994. Массовое сознание. Опыт определения и проблемы исследования. М.: Политиздат. 367 с. 
Дилигенский Г.Г. 1986. В поисках смысла и цели: проблемы массового сознания современного капиталистического общества. М.: Политиздат. 256 с.

Дюркгейм Э. 1991. О разделении общественного труда. Метод социологии. М.: Наука. 572 с.

Лебон Г. 1995. Психология народов и масс. СПб: Макет. 313 с.

Любивый Я.В. 1993. Современное массовое сознание: динамика и тенденции развития. Киев: Наукова думка. 141 с.

Малькова Т.П. 1992. Информационное общество: поиск социальных детерминант формирования массового, группового и индивидуального сознания. Современные социально-политические процессы и динамика массового сознания. М.: Изд-во МГТУ. С. 23-76.

Маркс К. 1956. Святое семейство, или критика критической критики. Против Бруно Бауэра и компании. - К. Маркс, Ф. Энгельс. Собрание сочинений. М.: Госполитиздат. Т. 2. С. 3-230.

Норт Д., Уоллис Д., Вайнгаст Б. 2011. Насилие и социальные порядки. М.: Изд-во Института Гайдара. 479 с.

Ортега-и-Гассет Х. 1989. Восстание масс. - Вопросы философии. № 3-4. С. 121122.

Патрушев С.В., Филиппова Л.Е. 2017. Дуализм массового сознания и типология массовой политики. - Политическая наука. № 1. С. 13-37.

Поливаева Н.П. 2009. Политическое сознание в условиях трансформации российского общества: дис. ... д.полит.н. М.: РГСУ. 462 с.

Разум на перепутье. Общественное сознание между прошлым и будущим (под ред. Ю.А. Красина - отв. ред., А.Б. Вебера, А.А. Галкина). 2017. М.: Аспект Пресс. 256 c.

Соловьев А.И. 2017. Массовое сознание и государственная политика: точки пересечения и проблемы взаимодействия. - Политическая наука. № 1. С. 186203.

Тард Г. 1892. Законы подражания (пер. с фр.). СПб: Изд-во Ф. Павленкова, тип. и лит. С.Ф. Яздовского и К. 378 с.

Холодковский К.Г. 2018. Непростые проблемы современного общественного сознания. - Полис. Политические исследования. № 3. С. 176-181.

POLIVAEVA Nadezhda Pavlovna, Dr.Sci. (Pol.Sci.), Associate Professor, Head of the Chair of Social-humanitarian and Financial-legal Disciplines, Voronezh Institute of the Federal Penitentiary Service of Russia (1A Irkutskaya St, Voronezh, Russia, 394072; nadezhda-polivaeva.n@yandex.ru)

\section{THEORETICAL REFLECTIONS ON MASS CONSCIOUSNESS: IS IT POSSIBLE TO FIND THE ESSENCE?}

\footnotetext{
Abstract. The article attempts to carry out a theoretical review and generalization of some of the key properties of mass consciousness identified by leading modern scientists. Its main content is contained in the title, which suggests the search for an answer to the question whether the phenomenon of mass consciousness has an essence. The author clears up the position of J. Baudrillard that the desire to clarify the content of the term of mass is truly absurd - it is an attempt to give meaning to something that does not have it. The author believes that there are invariant correlations between the basic term of mass and its derivative - mass consciousness. Through an attempt to find some stable properties of mass consciousness, the author denotes its essential content. The article deals with sociological, socio-psychological, activity and other approaches to the interpretation of mass consciousness, features that distinguish it from ordinary and specialized
} 
consciousness, as well as collective consciousness and public opinion. The development of problems of mass consciousness in the Soviet scientific literature was hindered by the fact that it was considered as an attribute of mass society and as an alternative to class-consciousness. The problem of layers and fields of mass consciousness and its historical types has not been properly investigated yet.

Keywords: mass consciousness, mass, mass activity, collective consciousness, collective unconscious, ordinary consciousness, public opinion, mass society, public consciousness

ОГАНИСьЯН Юлий Степанович - доктор исторических наук, профессор; главный научный сотрудник Института социологии ФНИСЦ РАН (117218, Россия, г. Москва, ул. Кржижановского, 24/35, кopn. 5; dorunat@gmail.com)

\title{
ПОСТСОВЕТСКИЙ ЛИБЕРАЛИЗМ: ОТ РЕФОРМЫ К РЕВОЛЮЦИИ?
}

\begin{abstract}
Аннотация. Автор анализирует феномен радикализации социально-политических взглядов идеологов постсоветского либерализма, которые, апеллируя к протестным настроениям масс, формируют идеи назревания новой - «антипутинской» - революции в России. Основываясь на данных социологических исследований, автор доказывает несостоятельность утверждений о наличии предреволюционной ситуации в стране, допуская вместе с тем возможность дестабилизации социально-политической обстановки при соединении радикал-либеральных идей с массовым протестным движением и внешней поддержкой несистемной оппозиции.
\end{abstract}

Ключевые слова: либерал-реформизм, революционная ситуация, социальное неравенство, несистемная оппозиция, протестное движение

$\Pi$ ризрак революции вновь обживает медийное пространство России, образуемое сетевыми структурами Интернета, телевидения, печати, становится актуальным предметом социально-политического дискурса. Что же это означает? Предвестие новой революции? Реальную угрозу великих потрясений, каковые страна неоднократно переживала в XX в.? Еще недавно казалось, что эта угроза навсегда осталась в прошлом. В общественном сознании укреплялось убеждение, что эпоха социальных катастроф в истории страны завершилась развалом Советского Союза, что «либеральная революция» 1990-х гг. вывела страну на путь мирного развития и демократических реформ. По данным социологических опросов начала нулевых годов, само понятие «революция» на ассоциативном уровне воспринималось позитивно лишь $11 \%$ россиян, негативно - 47\%, нейтрально - 42\% [Российское общество... 2016: 218].

Озадачивает то, что социальным источником алармистских и призывающих к революции сигналов служат не массовые настроения, а узкогрупповые устремления элитарной прослойки общества, интересы которой выражает несистемная либеральная оппозиция, традиционно чуждая всякому революционаризму. Так, историк, заместитель председателя Партии народной свободы (ПАРНАС) А.Б. Зубов утверждает, что антисоветский переворот 1990-х гг. был всего лишь неудавшимся «либеральным экспериментом», завершившимся предпринятой В.В. Путиным попыткой «рекоммунизации», противодействие которой требует сплочения демократических сил общества ${ }^{1}$.

\footnotetext{
1 «Это был переворот, поставивший крест на свободной России, и он не убран до сих пор»: историк Андрей Зубов о революции 1917-го. - Настоящее время. 05.11.2017. Доступ: https://www. currenttime.tv/a/28830828.html (проверено 04.03.2020).
} 